\title{
Meziyobukkal kökünde üç kanal bulunan üst birinci büyük azı dişinin endodontik tedavisi: Bir olgu sunumu*
}

\author{
Mukadder İnci Başer Kolcu', Erhan Özcan ${ }^{1}$
}

Selcuk Dental Journal, 2015; 1: 25-28

Basvuru Tarihi: 11 Aralık 2014 Yayına Kabul Tarihi: 19 Şubat 2015

\section{Endodontic treatment of maxillary first molar with three mesiobuccal canals: A case report}

One of the teeth with most complex root system and root canal anatomy are maxillary first molars. Maxillary molars having three separate mesiobuccal canals ending with three separate foramen are extremely rare. When planning endodontic treatment in these teeth, the clinical and radiographical anatomy should be considered. In clinical practice, cone-beam computed tomography is one of the most important diagnostic tools for fully assessing this rarely encountered morphology. The aim of this report is to present a case of a left maxillary first molar with three separate mesiobuccal canals ending with three separate foramen and to emphasise the importance of thorough assessment of the anatomy of the root canal before treatment.

\section{KEY WORDS}

Cone-beam computed tomography, maxillary first molar, root canal anatomy

Diş kök kanal morfolojilerinin bilinmesi, endodontik tedavinin planlanmasında ve uygulanmasında son derece önemli ve karmaşık bir konudur. Literatürde bu konu üzerine birçok çalışma yapılmıştır (Degerness ve Walter 2010, Rwenyonyi ve ark 2007, Sert ve Bayırlı 2004, Vertucci 1984). Klinik ve laboratuar çalışmalarında (Weine ve ark 1969, Acosta 1978, Degerness ve Walter 2010), diş gruplarından üst büyük azı dişlerinin kanal sayılarında ve konfigürasyonlarında birçok farklılıkların bulunduğu gösterilmiştir. Bu dişlerde karşılaşılan başarısız endodontik tedavilerin en önemli nedenlerinden birisi, özellikle meziyobukkal (MB) kökte bulunan ilave kanalların tespit edilmesinde, temizlenmesinde ve doldurulmasındaki yetersizliktir (Garg ve ark 2010).
Ülkemizde bu alanda yapılan çalışmalar incelendiğinde; in vitro operasyon mikroskobu kullanılarak maksiller molar dişlerin kök ve kanal sayılarının incelendiği bir çalışmada MB ikinci kanal bulunma oranının \%80 olduğu belirlenmiştir (Gorduysus ve ark 2001). Çalışkan ve ark'ın (1995), Türk popülasyonunda 1400 adet çekilmiş diş üzerinde yaptıkları çalışmalarında da bu oran \%65 olarak bulunmuştur. Türk popülasyonundaki maksiller ve mandibuler çekilmiş dişleri inceledikleri çalışmalarında, Sert ve Bayırlı (2004) ise bu oranı kadınlarda \%30.2, erkeklerde \% 35 olarak bulmuşlardır. Weine ve ark (1969) MB kökte iki kanal bulunma olasılığının bir kanal bulunma olasılığından daha yüksek olduğunu, vakaların \%86'sında MB kökte bulunan iki kanalın apekse 1-4 $\mathrm{mm}$ kala birleştiği, \%14'ünde ise kanalların farklı bir apikal foramen ile sonlandığını bildirmişlerdir. Sonradan yapılan çalışmalarda (Kulild ve Peters 1990, Ferguson ve ark 2005) MB kökte ikinci kanal bulunması olasılığının Weine ve ark tarafından bildirilenden çok daha yüksek olduğu gösterilmiştir. Günümüzde ise $\mathrm{MB} 2$ veya meziyolingual kanal olarak ifade edilebilen ilave bir kanalın bulunmasının normal olduğu kabul edilmektedir (Garg ve ark 2010, Weine ve ark 1969). MB kökte üç kanal bulunması olasılığı ise çok düşüktür ve üçüncü kanalın tespit edilmesi in vitro çalışmalara kıyasla in vivo koşullarda daha zordur. Degerness ve Walter (2010) konik ışınlı bilgisayarlı tomografi (CBCT) kullanarak üst birinci büyük azı dişinin MB kök morfolojisini değerlendirdikleri çalıșmada üçüncü kanal insidansının \%1.1

\footnotetext{
* Meziyobukkal kökünde üç kanal bulunan üst birinci büyük azı dişinin endodontik tedavisi: bir olgu sunumu” isimli yayın 8-10 Kasım tarihli İzmir'de gerçekleştirilen 20.EBDO Uluslararası Bilimsel Kongre ve Sergisi'nde poster bildirimi olarak sunulmuştur

${ }^{1}$ Selçuk Üniversitesi Diş Hekimliği Fakültesi Endodonti Anabilim Dalı, Konya
} 
olduğunu bildirmişlerdir. Ancak, MB kökte üç kanalın tespit edildiğini ve doldurulduğunu bildiren çok az sayıda olgu sunumu bulunmaktadır (Garg ve ark 2010, Acosta 1978, Kakkar 2012).

Bu makalede MB kökünde üç kanal bulunan bir üst sol birinci büyük azı dişinin başarılı endodontik tedavisi sunulmaktadır. Nadir olarak görülebilen bu morfoloji CBCT yardımı ile doğrulanmıştır.

\section{OLGU SUNUMU}

Otuz yaşında erkek bir hasta sol üst çenesindeki belirgin ve kendiliğinden başlayan ağrı şikayeti ile kliniğimize başvurdu. Hastanın alınan tıbbi hikayesinde herhangi bir sistemik hastalığının bulunmadığı öğrenildi. Klinik ve radyolojik incelemelerde sol üst çene birinci büyük azı dişinde derin bir çürük kavitesi tespit edildi. Elektrikli pulpa testine uzamış yanıt alınan hastada ilgili dişeti ve çevre dokuların muayenesinde şişlik veya fistül ağzı gibi bulgulara rastlanmadı. Dişin periodontal durumu normal olarak değerlendirildi ve cep oluşumu gözlenmedi. Hastanın soğuk ve sıcağa karşı artmış duyarlılığının ve son zamanlarda başlayan gece uykudan uyandıracak kadar şiddetli ağrılarının bulunduğu öğrenildi. Periapikal bölgede radyografik olarak herhangi bir değişikliğin gözlemlenmediği hastada (Şekil 1a), perküsyona hafif duyarlılık tespit edildi. Tüm bu bulgular değerlendirilerek irreversible pulpitis tanısı konuldu ve hastanın aydınlatılmış onamı alındıktan sonra diş endodontik tedavi için hazırlandı.

Periapikal infiltrasyon tekniği kullanılarak Ultracaine DS Fort (4\% artikain ile epinefrin 1/100000, Hoechst-Marion Roussel, Frankfurt, Almanya) ile lokal anestezi sağlandı. Lastik örtü uygulamasının ardından, elmas ve çelik rond frezler ile çürük temizlenerek endodontik giriş kavitesi açıldı. MB1, MB2, distobukkal ve palatinal kanallar tespit edildi. Koronal pulpa

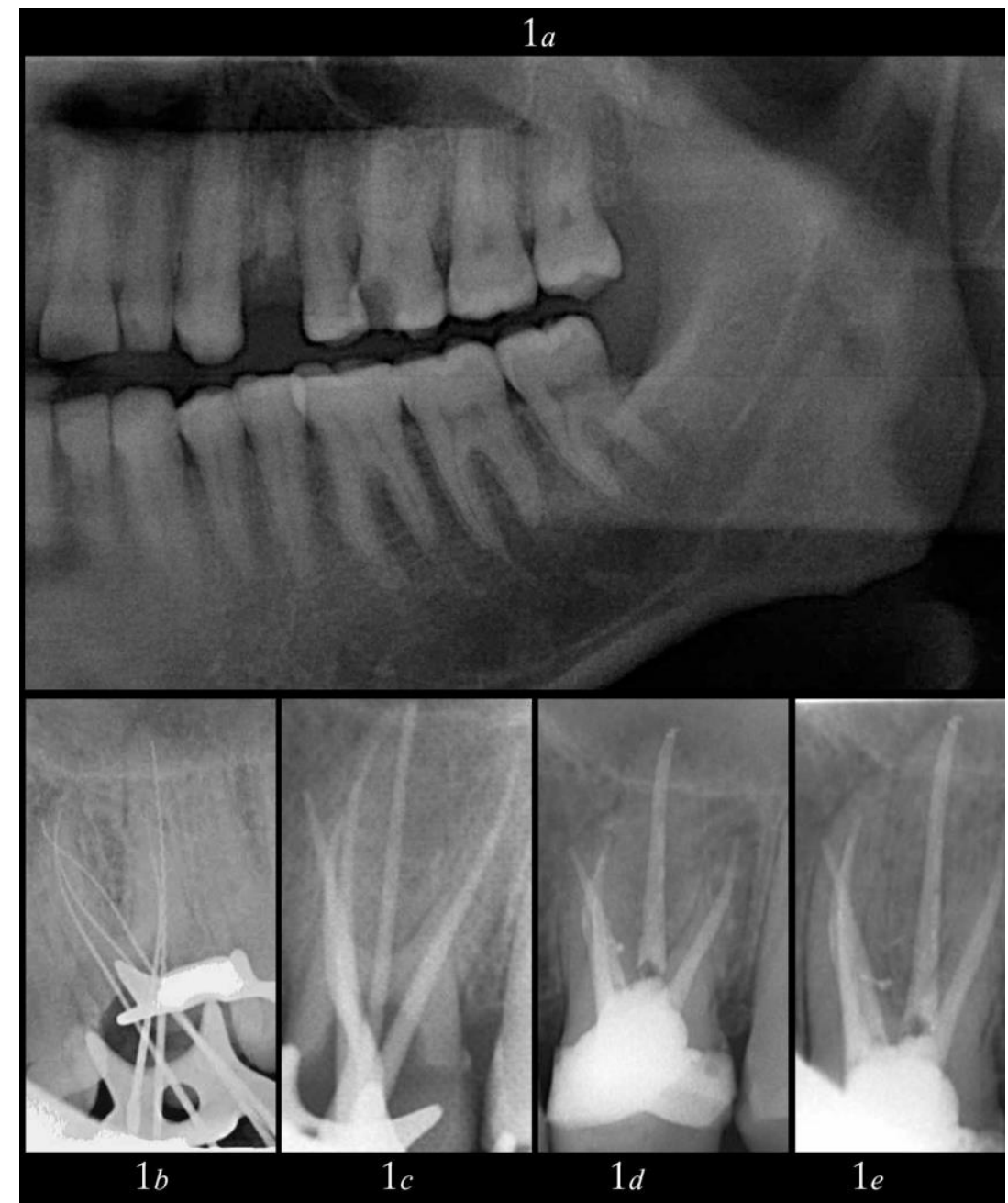

Şekil 1.

a Başlangıç panoromik filmin ilgili dişi gösterir yarısı

b Kanal boylarının belirlenmesi

c Güta-perkaların kontrol edilmesi

d Kök kanallarının dolgusunun radyografik görüntüsü

e Altı ay sonraki kontrol radyografik görüntüsü

dokusunun uzaklaştırılmasından sonra MB2 kanal ve palatinal kanal arasında ilave bir kanal daha olduğu görüldü. İlk dört kanalda 15 nolu K-tipi eğe ( SybronEndo; Glendora,CA, ABD) ile kanallara girilerek kanal boyunca ilerlendi. MB3 kanalda ise, 10 nolu eğe ile kanala giriş sağlanabildi. Çalışma boyutları bir apeks belirleyici cihaz ile belirlendi (Root ZX; Morita, CA, ABD) ve ayrıca radyografik olarak doğrulandı (Şekil 1b). Kanallar, ProTaper Universal döner sistem eğeleri (Dentsply Maillefer, Ballaigues, İsviçre) üreticinin talimatları doğrultusunda kullanılarak ve her eğe arasında $2 \mathrm{ml} \% 2,5^{\prime}$ lik $\mathrm{NaOCl}$ solüsyonu ile yıkanarak şekillendirildi. Kanal dolgusu yapılmadan önce güta perka uyumları radyografi ile kontrol edildi (Şekil 1c). Son yıkamada sırasıyla 2'şer ml \%17'lik EDTA, \%2,5'lik $\mathrm{NaOCl}$, serum fizyolojik ve \%2'lik klorheksidin kullanıldı. Kanallar steril kağıt koniler ile kurulandıktan sonra uygun açılı güta perkalar (Dentsply Maillefer) ve AH Plus (Dentsply Destrey, Konstanz, Almanya) kanal dolgu patı ile dolduruldu (Şekil 1d). Kanal tedavisi tamamlanan dişin üst restorasyonu kompozit dolgu materyali (3M, St. Paul, Minn, ABD) ile restore edildi. 
Kök kanal tedavisi sonrasında alınan radyografide süperpozisyona bağlı olarak MB kanallar tam olarak görülemedi. İlgili bölgeden kısmi CBCT taraması yapıldı ve kök kanal morfolojisini değerlendirmek için farklı seviyelerde transvers kesitler elde edildi. Bu kesitlerde MB kökte üç ayrı apekse sahip üç adet MB kanal olduğu görüldü (Şekil 2). Hasta kontrol için bir ay sonra çağrıldığında dişini fonksiyonel olarak kullanabildiği öğrenildi. Yapılan ağız içi muayenesinde perküsyon, palpasyon, ağrı, şişlik gibi bulgulara rastlanılmadı. Altı aylık kontrol radyografisinde periapikal patoloji lehine bulguya rastlanılmadı (Şekil1e).

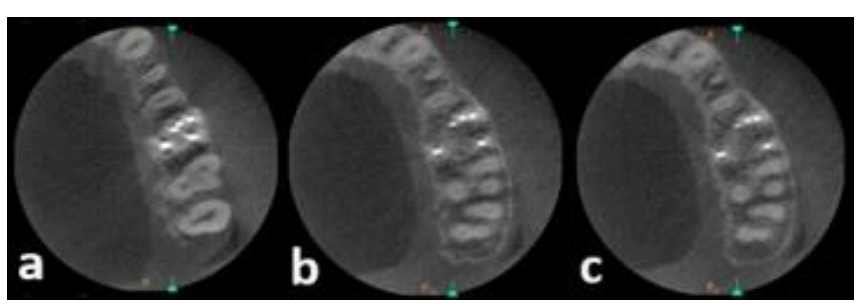

Șekil 2.

Kanal dolgusu tamamlanan dişin bilgisayarlı tomografi görüntüsü

a Servikal Üçlüdeki Görüntü

b Orta Üçlüdeki Görüntü

c Apikal Üçlüdeki Görüntü

\section{TARTIŞMA}

Üst birinci büyük azı dişlerinin kök kanal anatomisinde birçok varyasyon belirlenmiştir. Bunlardan MB kökte üçüncü kanalın gözlenmesi oranın \%0,4 ile \%2,3 arasında olduğu ifade edilmiştir (Acosta 1978, Al Shalabi ve ark 2000). Acosta'nın (1978) üst birinci büyük azı dişlerinin pulpa odasını büyüteç ve 0.08 mm'lik eğelerle incelediği çalışmada MB üçüncü kanal bulunma olasılığı \%2,3 iken; Al Shalabi ve ark (2000) bu oranı \%1 olarak bulmuşlardır. Rwenyonyi ve ark (2007) ve Neaverth ve ark'nın (1987) yaptıkları klinik çalışmalarda ise üçüncü MB kanalın bulunma oranı sırasıyla $\% 0,5$ ve $\% 0,4$ 'e şeklinde belirlenmiştir. Anatomik varyasyonların bulunma oranları incelendiğinde in vitro çalışmalarda in vivo çalışmalara göre daha yüksek oranlar gösterilmiştir. Bu çalışmalar arasındaki bu farklılığı belirlemek üzere Seidberg ve ark'ın (1973) yaptıkları bir çalışmada, 201 üst birinci büyük azı dişi incelemiş ve MB ikinci kanal bulunma oranı in vivo \%33,3 iken in vitro \%62 olarak belirlenmiştir.
Yayınlanan olgu sunumları da incelendiklerinde üçüncü MB kanal bulunan vakalarda, kanalların sıklıkla 3 ayrı kanal olarak başlayıp apikalde MB2 ile MB3'üncü kanalın birleştiği görülmektedir (Vertucci tip1+tip 4) (Garg ve ark 2010, Ferguson ve ark 2005, tip1+tip 4) (Garg ve ark 2010, Ferguson ve ark 2005, Kakkar 2012). Günümüze kadar çok sınırlı sayıda olgu sunumunda üst birinci büyük azı dişinde Vertucci tip 8 (kanalların ayrı kanal ağızları ile başlayıp, seyirleri sırasında anastamoz gözlenmediği ve ayrı forminalardan kökleri terk ettiği) sınıfına uygun MB kanal bulunduğu rapor edilmiştir (Martinez ve Ruiz 1983, Beatty 1984). Bu olgu sunumu da Vertucci tip 8 sınıfında olması ile oldukça nadir görülen bir sınıflamaya sahiptir.

Ekstra kanalların, küçük boyut özellikleri ve diğer kanallarla süperpozisyonlarından dolayı klinikte tespit edilmesi oldukça zor olabilir. Geleneksel ağız içi periapikal radyograflar kök kanal morfolojisinin değerlendirilmesinde önemli teşhis araçlarıdır. Fakat elde edilen görüntülerin 2-boyutlu olması nedeni ile ekstra kanallar hakkında tam bir bilgi sağlayamayabilirler. Son zamanlarda CBCT'nin geliştirilmesi ve endodontik tedavide kullanılmasıyla, farklı açılardan elde edilen periapikal filmlerle bile gözden kaçırılabilen kanallar kolaylıkla tespit edilebilmektedir (Joseph ve ark 2012). Durack ve Patel (2012) yayımladıkları literatür derlemesinde CBCT taraması için verilen radyasyon dozunun geleneksel ağız içi radyograflar için verilenden yüksek olduğunu ve bu nedenle, geleneksel radyografiler ile çözülemeyen problemlerde olguya özgü olarak CBCT'ye başvurulması gerektiğini vurgulamışlardır. Bu olgu sunumunda çok nadir rastlanan bir vaka olması ve endodontik tedavi literatürüne katkı sağlayacağı düşünülerek, dolgu sonrası kanalların konfigürasyonlarını 3-boyutlu olarak gösterebilmek amacı ile sınırlı CBCT görüntüsü elde edilmiştir.

\section{SONUÇ}

Endodontik tedavi esnasında, her bir dişin kök kanal morfolojisinde muhtemel anatomik sapmalar olabileceği düşünülmelidir. Bu muhtemel sapmalardan birisi de üst birinci büyük azı dişinin MB kökünde üç kanal bulunmasıdır. 


\section{Meziyobukkal kökünde üç kanal bulunan üst birinci büyük azı dişinin endodontik tedavisi: Bir olgu sunumu}

Üst birinci büyük azı dişi, en karmaşık kök ve kanal anatomisine sahip dişlerden birisidir. $\mathrm{Bu}$ dişin meziyobukkal kökünde üç ayrı foramen ile sonlanan üç kanal bulunması ise oldukça nadir görülen bir olgudur. Böyle bir dişe endodontik tedavi uygulanacağı zaman, klinik ve radyografik anatomisinin farkında olunmalıdır. Klinikte nadir olarak karşılaşılan morfolojilerin, tam bir değerlendirilmesinin yapılabileceği en önemli tanı araçlarından biri konik ışınlı bilgisayarlı tomografidir. Bu makalenin amacı meziyobukkal kökünde ayrı foramenler ile sonlanan, üç kanal bulunan üst sol birinci büyük azı dişine ait bir olguyu sunmak ve kök kanal anatomisi hakkında tam bir bilgiye sahip olmanın önemini vurgulamaktır.

\section{ANAHTAR KELIMELER}

Konik ışınlı bilgisayarlı tomografi, kök kanal anatomisi, maksiller birinci büyük azı dişi

\section{KAYNAKLAR}

Acosta V SA TBS, 1978. Anatomy of the pulp chamber floor of the permanent maxillary first molar. J Endod, 4(7), 214-223.

Al Shalabi RM, Omer OE, Glennon J, Jennings M, Claffey NM, 2000. Root canal anatomy of maxillary first and second permanent molars. Int Endod J, 33(5), 405-414.

Beatty RG, 1984. A five-canal maxillary first molar. J Endod,10(4),156-157.

Caliskan MK, Pehlivan Y, Sepetcioglu F, Turkun M, Tuncer SS, 1995. Root canal morphology of human permanent teeth in a Turkish population. J Endod, 21: 200-204.

Degerness R. A. Walter R. B, 2010. Dimension, anatomy and morphology of the mesiobuccal root canal system in maxillary molars. J Endod, 36(6), 985-989.

Durack C, Patel S, 2012. Cone beam computed tomography in endodontics. Brazilian dental journal, 23(3),179-191.

Ferguson DB, Kjar KS, Hartwell GR, 2005. Three canals in the mesiobuccal root of a maxillary first molar: a case report. J Endod, 31(5), 400-402.
Garg AK, Tewari RK, Kumar A, Agrawal N, 2010. Endodontic treatment of a maxillary first molar having three mesiobuccal canals with the aid of spiral computed tomography: a case report. Journal of oral science, 52(3),495-499.

Gorduysus MO, Gorduysus M, Friedman S, 2001. Operating microscope improves negotiation of second mesiobuccal canals in maxillary molars. J Endod, 27(11),683-686.

Joseph P KS, Krishna Vel, Manivasagam Chokkalingam, Raju Rahna, 2012. Endodontic management of a maxillary first molar with five canals with the aid of cone beam computed radiography: a case report. International Research Journal Of Pharmacy, 3(12),88-90.

Kakkar P, Singh A, 2012. Maxillary first molar with three mesiobuccal canals confirmed with spiral computer tomography. Journal of clinical and experimental dentistry, 4(4), 256-259.

Kulild JC, Peters DD, 1990. Incidence and configuration of canal systems in the mesiobuccal root of maxillary first and second molars. J Endod,16(7), 311-317.

Martinez B A, Ruiz-Badanelli P, 1983. Maxillary first molars with six canals. J Endod, 9(9), 375-381.

Neaverth EJ, Kotler LM, Kaltenbach RF,1987. Clinical investigation (in vivo) of endodontically treated maxillary first molars. J Endod,13(10):506-512.

Rwenyonyi CM, Kutesa AM, Muwazi LM, Buwembo W, 2007. Root and canal morphology of maxillary first and second permanent molar teeth in a Ugandan population. Int Endod J, 40(9),679-683.

Seidberg BH, Altman M, Guttuso J, Suson M, 1973. Frequency of two mesiobuccal root canals in maxillary permanent first molars. Journal of the American Dental Association, 87(4):852-856.

Sert S, Bayırlı GS, 2004. Evaluation of the root canal configurations of the mandibular and maxillary permanent teeth by gender in the Turkish population. J Endod, 30: 391398.

Vertucci FJ, 1984. Root canal anatomy of the human permanent teeth, 1984. Oral surgery, oral medicine, and oral pathology,58(5),589-599.

Weine FS, Healey HJ, Gerstein H, Evanson L, 1969. Canal configuration in the mesiobuccal root of the maxillary first molar and its endodontic significance. J Endod, 38(10):13051308.

Yazışma Adresi:

M.İnci BAŞER KOLCU

Selçuk Üniversitesi

Diş Hekimliği Fakültesi Endodonti AD

Konya

Tel:+90 (505) 5306180

incikolcu@gmail.com 